\title{
O design da cadeira de rodas infantil e o processo de exclusão/inclusão social: uma revisão integrativa da literatura
}

\section{Design of the child wheelchair and the process of social exclusion/inclusion: an integrating literature review}

El design de la silla de ruedas infantil y el proceso de exclusión/ inclusión social: una revisión integral de la literatura

\author{
Camila Dalsin ${ }^{1}$ \\ Bruna Haubert ${ }^{2}$ \\ Jacinta Sidegum Renner ${ }^{3}$ \\ Claudia Schemes ${ }^{4}$
}

${ }^{1}$ Bacharel em Moda e Mestranda em Diversidade Cultural e Inclusão Social pela Universidade Feevale (Novo Hamburgo, RS). Bolsista PROSUC/CAPES. E-mail: cadalsin@hotmail.com, Orcid: http://orcid.org/0000-0003-2201-2558

${ }^{2}$ Graduanda em Design pela Universidade Feevale, Novo Hamburgo, RS. E-mail: brunahaubert@gmail.com, Orcid: http://orcid.org/0000-0002-5532-9984

${ }^{3}$ Doutora em Engenharia de Produção com ênfase em Ergonomia pela Universidade Federal do Rio Grande do Sul (UFRGS), Porto Alegre, RS. Docente no Programa de Pós-Graduação em Diversidade Cultural e Inclusão Social da Universidade Feevale (Novo Hamburgo, RS). E-mail: jacinta@feevale.br, Orcid: http://orcid.org/0000-0002-9904-4710

${ }^{4}$ Doutora em História pela Pontifícia Universidade Católica do Rio Grande do Sul (PUC-RS). Docente no Programa de Pós-Graduação em Processos e Manifestações Culturais da Universidade Feevale, Novo Hamburgo, RS. E-mail: claudias@feevale.br, Orcid: http://orcid.org/0000-0001-8170-9684 
Resumo: Tendo em vista a contribuição do design no desenvolvimento das Tecnologias Assistivas (TA), propõe-se neste artigo uma revisão integrativa da literatura. O objetivo geral é verificar na literatura brasileira os artigos que versam sobre processo de exclusão-inclusão social, cadeira de rodas, aspectos lúdicos e saúde dos usuários de cadeira de rodas infantil. Serão analisados artigos e produções científicas disponíveis no período de 2007 a 2017, na base de dados da CAPES, com as seguintes palavras chave: cadeira de rodas, crianças, aspectos lúdicos e inclusão social. Este levantamento permitiu a identificação de lacunas e o incentivo para novos estudos, tal como a pertinência em avançar em pesquisas minuciosas que venham a contemplar o público infantil no redesenho da cadeira de rodas, visando à inclusão social, considerando os parâmetros ergonômicos necessários para o reprojeto e dando destaque para os aspectos lúdicos da infância.

Palavras-chave: cadeira de rodas; deficiência infantil; inclusão social; lúdico.

Abstract: Considering the contribution of design in the development of Assistive Technologies (TA), this article proposes an integrative review of the literature. The general objective is to verify in the Brazilian literature the articles that deal with the process of exclusion-social inclusion, wheelchair, playful aspects and health of children wheelchair users. Articles and scientific productions available from 2007 to 2017, in the CAPES database, will be analyzed with the following keywords: wheelchair, children, play aspects and social inclusion. This survey allowed the identification of gaps and the incentive for new studies, as well as the pertinence to advance in detailed researches that will contemplate the children's public in the redesign of the wheelchair, aiming at social inclusion, considering the ergonomic parameters necessary for the redesign and highlighting the playful aspects of childhood.

Keywords: wheelchair; child disability; social inclusion; ludic.

Resumen: Teniendo en cuenta la contribución del diseño en el desarrollo de las Tecnologías Asistivas (TA), se propone en este artículo una revisión integrativa de la literatura. El objetivo general es verificar en la literatura brasileña los artículos que versan sobre proceso de exclusión-inclusión social, silla de ruedas, aspectos lúdicos y salud de los usuarios de silla de ruedas infantil. Se analizarán artículos y producciones científicas disponibles en el período de 2007 a 2017, en la base de datos de CAPES, con las siguientes palabras clave: silla de ruedas, niños, aspectos lúdicos e inclusión social. Este levantamiento permitió la identificación de lagunas y el incentivo para nuevos estudios, así como la pertinencia en avanzar en investigaciones minuciosas que vengan a contemplar al público infantil en el rediseño de la silla de ruedas, visando la inclusión social, considerando los parámetros ergonómicos necesarios para el reproyecto y destacando los aspectos lúdicos de la infancia.

Palabras clave: silla de ruedas; discapacidad infantil; inclusión social; juguetón. 
O design da cadeira de rodas infantil e o processo de exclusão/inclusão social: uma revisão integrativa da literatura

\section{INTRODUÇÃO}

De modo geral, o percentual de crianças com deficiência vem crescendo ao longo das últimas décadas, porém ainda se trata de um grupo minoritário. Em alguns casos, as crianças podem apresentar deficiências múltiplas incluindo, além das motoras, as de linguagem, o que dificulta a sua comunicação e interação com o mundo.

Quando se trata de crianças com deficiência que necessitam do uso da cadeira de rodas, há que se trazer à discussão as Tecnologias Assistivas (TA), que nada mais são do que mecanismos/dispositivos utilizados para substituir funções do corpo que não ocorrem adequadamente. Nesse contexto, menciona-se a cadeira de rodas como uma TA que funciona como uma extensão do corpo. Portanto a cadeira de rodas é uma TA que oportuniza a locomoção e o direito de ir e vir, que é uma atividade essencial para a manutenção da autonomia e da qualidade de vida, propiciando à criança o desenvolvimento de suas potencialidades.

Em se tratando do público infantil usuário de cadeira de rodas, existe a tendência de estigmatizar a criança por não corresponder ao padrão social, fato que pode contribuir para a exclusão e potencializar o estranhamento com o corpo social, seja no ambiente escolar, familiar ou na comunidade na qual está inserida. A partir disso, é importante ressaltar que é justamente na fase da infância que se formam os estigmas oriundos da convivência social e pessoal.

Entretanto o design emocional e os aspectos lúdicos adaptados à cadeira de rodas infantil podem minimizar o processo de exclusão que tende a estar imbricado nessa relação usuário- produto- corpo social. Os produtos, no caso da cadeira de rodas que é essencial para a vida social da criança com deficiência, carregam consigo significados que podem auxiliar na construção da identidade do sujeito que os utiliza.

Partindo desse pressuposto, este estudo foi norteado pela seguinte questão de pesquisa: 'Existem estudos que contemplem cadeiras de rodas destinadas ao público infantil com apelo lúdico visando à promoção da inclusão social?' O objetivo geral foi verificar se, na literatura brasileira, há subsídios para discussão dos aspectos lúdicos adaptados à cadeira de 
rodas infantil e em que proporção elas são mencionadas como fatores que promovem o conforto, a saúde e a exclusão-inclusão social das crianças.

\section{METODOLOGIA}

O presente estudo está embasado em uma abordagem qualitativa para a identificação de produções científicas sobre o design da cadeira de rodas infantil como ferramenta de inclusão social, entre o período de 2007 e 2017, buscando promover "uma discussão por meio de referenciais teóricos publicados, analisando e discutindo as várias contribuições científicas" (BERLESE et al., 2015, p. 26). Foi elegido a revisão integrativa da literatura, que tem como premissa "Iocalizar, analisar, sintetizar e interpretar a investigação prévia [...] relacionada com a sua área de estudo; é, então, uma análise bibliográfica pormenorizada, referente aos trabalhos já publicados sobre o tema" (BENTO, 2012, p. 42).

A coleta dos artigos foi realizada por meio da Biblioteca Virtual da CAPES - Catálogo de Teses e Dissertações. Os descritores utilizados foram "cadeira de rodas", "criança", "inclusão social", "infantil", "lúdico", "redesenho" e "redesign". A busca foi realizada em três etapas: na primeira, utilizou-se os descritores "cadeira de rodas" AND "criança" AND "lúdico" AND "inclusão social"; na segunda, "cadeira de rodas" AND "infantil" AND "redesenho" AND "inclusão social"; e, na terceira, "cadeira de rodas" AND "infantil" AND "redesign" AND "inclusão social".

Foram estabelecidas como critérios de inclusão para a seleção dos estudos somente teses e dissertações publicadas no período de 2007 a 2017, em língua portuguesa, disponibilizadas na íntegra. Os critérios de exclusão contemplam os estudos indisponíveis na íntegra, escritos em língua estrangeira e que não pertencem ao período selecionado.

A seleção foi feita respectivamente pela leitura dos títulos, resumos e teses e/ou dissertações, conforme a Figura 1. Foram selecionadas dez dissertações e nenhuma tese. As publicações repetidas em mais de uma base de descritores (seis dissertações no total), foram analisadas uma única vez. Após a aplicação dos critérios inclusão, a amostra limitou-se a quatro dissertações. É importante ressaltar que não se encontrou dissertação ou tese com todos os descritores desejados. 
Figura 1 - Seleção de teses/dissertações no Banco Virtual da CAPES

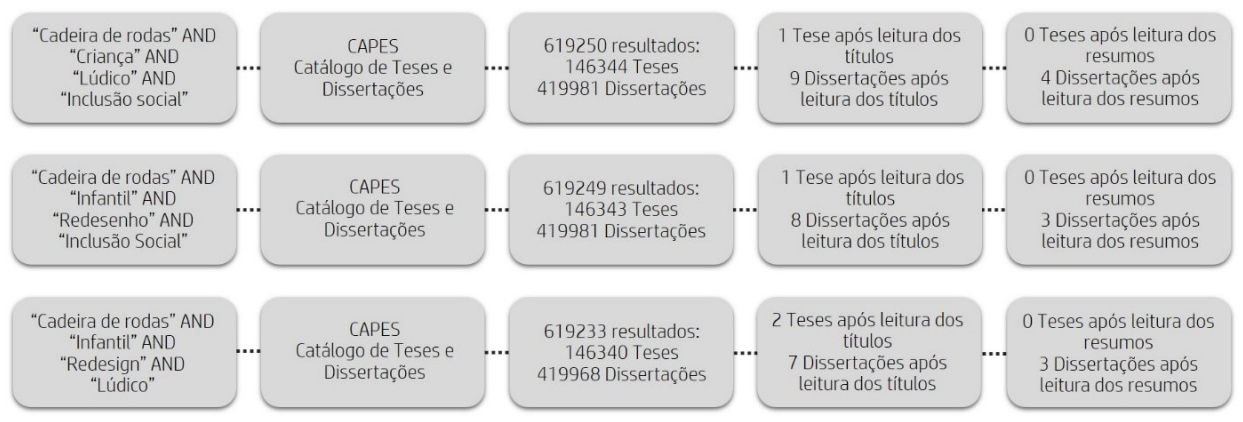

Fonte: Elaborado pelas autoras (2018).

Para a realização desta revisão, foram sugeridas as respectivas etapas: identificação do tema; seleção da questão de pesquisa; estabelecimento de critérios para inclusão e exclusão de estudos/amostragem na literatura; definição das informações a serem extraídas dos estudos selecionados; avaliação dos estudos incluídos e apresentação da revisão integrativa (MENDES; SILVEIRA; GALVÃO, 2008).

\section{APRESENTAÇÃO DOS RESULTADOS}

No processo de busca eletrônica ao banco de teses e dissertação CAPES, foram identificadas dez pesquisas. Entretanto, para a presente revisão integrativa, foram analisadas somente as quatro que atenderam aos critérios de inclusão previamente estabelecidos. Considerando a proporção de dissertações publicadas por ano, todas apresentaram uma publicação. Contudo, nos anos de 2011, 2013, 2014, 2015 e 2016, não foi possível localizar pesquisas que pudessem ser incluídas neste estudo devido às palavras-chave não terem sido encontradas na base de dados da CAPES.

O Quadro 1 apresenta os artigos selecionados com título, ano e natureza de estudo, respectivamente. 
Quadro 1 - Síntese dos resultados quanto às variáveis- título, ano, natureza do estudo e autor(a)

\begin{tabular}{|c|c|c|c|c|}
\hline Ref. & Autor(a) & Ano & Título da Dissertação & $\begin{array}{l}\text { Natureza do } \\
\text { estudo }\end{array}$ \\
\hline 1 & $\begin{array}{l}\text { Brunna Michelle } \\
\text { Paiva de Amorim }\end{array}$ & 2009 & $\begin{array}{l}\text { Uma contribuição crítica para } \\
\text { o redesenho de cadeira de } \\
\text { rodas adaptada para crianças } \\
\text { e adolescentes com paralisia } \\
\text { infantil }\end{array}$ & Quantitativa \\
\hline 2 & $\begin{array}{l}\text { Natássia Leilane } \\
\text { Schmitt }\end{array}$ & 2010 & $\begin{array}{l}\text { Tecnologias assistivas no } \\
\text { cotidiano da criança com } \\
\text { deficiência física: potencialidades } \\
\text { e inclusão social }\end{array}$ & Qualitativa \\
\hline 3 & $\begin{array}{l}\text { Carlos Eduardo } \\
\text { Senna }\end{array}$ & 2012 & $\begin{array}{l}\text { Tecnologia assistiva nas classes } \\
\text { comuns do ensino regular: } \\
\text { contribuições no design de } \\
\text { sistemas de mobilidade infantil } \\
\text { para auxílio nas interações } \\
\text { sociais. }\end{array}$ & Qualitativa \\
\hline 4 & $\begin{array}{l}\text { Liara de Mucio } \\
\text { de Mattos }\end{array}$ & 2017 & $\begin{array}{l}\text { Julgamento visual de cadeira } \\
\text { de rodas: contribuições para o } \\
\text { design de produtos assistivos }\end{array}$ & Quantitativa \\
\hline
\end{tabular}

Fonte: CAPES (2018).

Considerando-se que os quatro artigos encontrados atenderam ao escopo de busca, foi possível explorá-los individualmente e em sequência datada por ano de publicação. Das quatro dissertações encontradas, duas são da área de Design, uma de Engenharia de Produção e uma de Inclusão Social e Acessibilidade.

\section{DISCUSSÃO}

Ao abordar sobre a deficiência e os impactos que ela causa na vida das pessoas, primeiramente, é necessário entender o que ela representa. Para lida e Guimarães (2016, p. 699), pessoas com deficiência "são aquelas que apresentam algum tipo de limitação funcional ou cognitiva, não podendo exercer plenamente as suas aptidões físicas e/ou mentais, temporária ou permanentemente". Essas deficiências podem interferir no desenvolvimento 
O design da cadeira de rodas infantil e o processo de exclusão/inclusão social: uma revisão integrativa da literatura

do indivíduo, tanto na aprendizagem como nas relações familiares e/ou na construção da sua personalidade.

Ao longo das últimas décadas, o percentual das pessoas com deficiência aumentou. No Brasil, esse número corresponde a 45,6 milhões de pessoas, representando $23,9 \%$ da população, dentre os quais, 25.800 .681 são mulheres (26,5\%) e 19.805.367 são homens (21,2\%) (OLIVEIRA, 2012 ). Apesar da proporção de pessoas com pelo menos uma deficiência ser maior entre adultos e idosos, percebe-se crescimento relevante na percentagem do público infantil na faixa etária de 0 a 14 anos, totalizando 3.459.401 indivíduos (7,5\%) (INSTITUTO BRASILEIRO DE GEOGRAFIA E ESTATÍSTICA [IBGE], 2010), sendo que desses, 2,39\% relatam de acordo com a sua percepção apresentar alguma deficiência severa (OLIVEIRA, 2012). O aumento da sobrevida de recém-nascidos com distúrbios graves é uma das causas básicas responsáveis pelo aumento do índice de deficiência no Brasil (LARANJEIRA; ALMEIDA, 2008).

Um panorama geral sobre a deficiência motora indica que esta ocupa o segundo lugar de maior prevalência na população, totalizando cerca de 7\% dos brasileiros (OLIVEIRA, 2012). Dependendo do grau de limitação na mobilidade do indivíduo, necessita-se o uso de cadeira de rodas. O produto é uma Tecnologia Assistiva (TA), que, por definição da ASSOCIAÇÃO BRASILEIRA DE NORMAS TÉCNICAS (ABNT, 2005, p. 04), é um "conjunto de técnicas, aparelhos, instrumentos, produtos e procedimentos que visam auxiliar a mobilidade, percepção e utilização do meio ambiente e dos elementos por pessoas com deficiência".

Por ser utilizada diariamente na posição sentada durante longos períodos, é fundamental que haja uma reflexão acerca do conforto da cadeira de rodas. Corrêa e Boletti (2015) definem o termo conforto como a sensação de alívio, bem-estar e comodidade. Em relação à sensação de bem-estar experimentada pelas pessoas que permanecem muito tempo sentadas, ela está diretamente ligada com a sua qualidade de vida (KROEMER; GRANDJEAN; 1998).

Para contextualizar a qualidade de vida, Minayo, Hartz e Buss (2000) a define em termos da saúde, como sendo a dinâmica que possibilita ao enfermo técnicas de melhoria na sua condição de vida após situações de lesão 
física ou biológica, propiciando o desenvolvimento de suas potencialidades. Ao ponderar-se sobre a qualidade de vida do público usuário de cadeira de rodas, pensa-se em dignidade, respeito, possibilidade de autonomia e controle da sua própria vida (MASINI et al., 1997), além de inclusão social.

A partir dos padrões estabelecidos pela sociedade cujas pessoas são influenciadas a os seguir, sabe-se que a saúde e o controle sobre o corpo têm grande valor (BERLESE et al., 2015). Portanto todos os indivíduos que se distanciam do modelo social corporal tendem a serem estigmatizados, fato esse que contribui para a exclusão da criança com deficiência e potencializa o estranhamento com o corpo social no qual está inserida. Conforme Goffman (1988), a sociedade rotula as pessoas que apresentam alguma deformidade como "estragadas" e/ou "diminuídas", reduzindo-lhes as oportunidades de vida e, consequentemente, abrindo lacunas para o surgimento do bullying. Normalmente, o termo é usado para designar tratamentos grosseiros e é praticado por pessoas autoritárias como forma de se impor sobre aquelas que consideram mais fracas (HIRIGOYEN, 2002).

Diante desse quadro crítico, o design emocional e os aspectos lúdicos aliados à cadeira de rodas infantil podem minimizar o contexto de exclusão vivenciado pelas crianças usuárias dessa tecnologia assistiva. Norman (2008, p. 11) defende que os produtos não possuem apenas formas físicas e funções mecânicas, mas também "assumem forma social e funções simbólicas", que são responsáveis pela inclusão social e pela construção de significados na vida de seus usuários. Russo e Hekkert (2008, p. 35) comentam que as pessoas possuem afeição pelos produtos utilizados e que estes "encorajam e facilitam a construção e familiarização da autoidentidade de uma pessoa".

Provindo dessa contextualização, o processo de inclusão social mostra-se necessário. Sassaki (2010, p. 39) conceitua-o como o "processo pelo qual a sociedade se adapta para poder incluir, em seus sistemas sociais gerais, pessoas com deficiência (além de outras) e, simultaneamente, estas se preparam para assumir seus papéis na sociedade". Logo, a cadeira de rodas pode vir a ser uma facilitadora nesse processo.

Instrumento considerado de suma importância na reabilitação social das pessoas com deficiência física, a cadeira de rodas foi o objeto de estudo da pesquisa de Amorim (2009) através de uma análise crítica que 
O design da cadeira de rodas infantil e o processo de exclusão/inclusão social: uma revisão integrativa da literatura

contemplou quatro modelos disponíveis no mercado nacional. Além de caracterizar as vantagens e desvantagens de cada tipo, o estudo propôs técnicas de readaptação da cadeira de rodas de acordo com as necessidades do público investigado, ou seja, crianças com paralisia cerebral do tipo tetraparética na faixa etária de 5 a 12 anos.

Em sua pesquisa, Schmitt (2010) analisou a utilização das TA no dia a dia de crianças com deficiência física, objetivando averiguar a contribuição desses dispositivos no desenvolvimento infantil e no processo de inclusão social. Para tanto, a avaliação teve como auxílio a elaboração de dois produtos: uma cadeira para banho e uma cadeira para uso em sala de aula. Os resultados indicaram que as TA oportunizam ao público infantil com deficiência estar presente em diferentes ambientes sociais, favorecendo- Ihe participar das atividades cotidianas. Também, a autora relatou que o ambiente no qual a criança com deficiência está inserida tem papel fundamental na sua estruturação física e subjetiva.

Já a proposta apresentada por Senna (2012) em seu estudo visou auxiliar no processo de interação social do público infantil com deficiência física no contexto escolar, através de contribuições no design da cadeira de rodas como sistemas de mobilidade infantil. Para tanto, a sua pesquisa contemplou quatro objetivos específicos: delinear o perfil dos principais recursos assistivos de locomoção destinados a esse público; identificar os requisitos projetuais fundamentais para um estudante com deficiência; gerar projetos de produto que correspondam às especificações do projeto; e detalhar a concepção gerada para assessorar a construção de um protótipo.

As pessoas tendem a associar os produtos com a personalidade de quem o utiliza. A cadeira de rodas, por sua vez, apresenta uma aparência hospitalar, fazendo com que o usuário acabe sendo avaliado de forma negativa. Seguindo esse raciocínio, Mattos (2017) teve como propósito avaliar o julgamento visual das cadeiras de rodas manuais por indivíduos não usuários a fim de verificar se há relação entre as características de design do produto e as percepções negativas relacionadas a quem o usa. Os resultados revelaram que a cadeira de rodas implica o julgamento negativo sobre os usuários e que este é provocado pela aparência do produto. 
Para apresentar os resultados obtidos, optou-se por separar em cinco categorias: as TA e a cadeira de rodas; aspectos ergonômicos e de conforto da cadeira de rodas; estigma, bullying e exclusão social; design emocional, ludicidade e inclusão social, e redesenho da cadeira de rodas.

\subsection{As tecnologias assistivas (TAs) e a cadeira de rodas}

Todos os estudos abordaram sobre as TAs. Com objetivo de auxiliar as pessoas com deficiência, esses recursos promovem qualidade de vida, inclusão social e a possibilidade de independência (BERSCH, 2009). Ainda, segundo Laranjeira e Almeida (2008), as TAs melhoram a autoestima e a qualidade de vida dos indivíduos que necessitam utilizá-las a partir do momento em que aumentam a sua capacidade funcional, assim como elevam as chances do sujeito de participação ao corpo social, seja na integração das tarefas escolares e/ou no retorno ao trabalho.

Segundo Schmitt (2010), as TAs podem ser caracterizadas e contextualizadas sob determinados pontos de vista: assistiva versus reabilitadora e educacional; simples e sofisticada; concreta e teórica; equipamentos versus instrumentos; geral versus específica, e comercializada e individualizada. Além disso, em seus estudos, a autora menciona um conceito essencial relacionado às tecnologias assistivas: o Design Universal. O projeto universal (universal design), também denominado de inclusivo (inclusive design), "estabelece que produtos, prédios e espaços sejam acessíveis, ao máximo possível, de todas as pessoas" (IIDA; GUIMARÃES, 2016, p. 704).

O objeto de estudo de Amorim (2009), Senna (2012) e Mattos (2017) foi a cadeira de rodas. Schmitt (2010), por sua vez, discutiu sobre as possíveis tecnologias assistivas utilizadas no desenvolvimento infantil, tais como auxílios para a vida diária, comunicação aumentativa (suplementar) ou alternativa, recursos de acessibilidade no computador, sistema de controle de ambiente, projetos arquitetônicos para acessibilidade, órteses e próteses, adequação postural, auxílios de mobilidade, auxílios para cegos ou com visão subnormal, auxílio para surdos ou com déficit auditivo, e adaptações para veículos. Ainda, conforme a autora, a prescrição e a confeç̧ão dos dispositivos tecnológicos devem corresponder ao estilo de vida e as caracte- 
O design da cadeira de rodas infantil e o processo de exclusão/inclusão social: uma revisão integrativa da literatura

rísticas individuais de cada criança usuária.

Também conhecida como mobilidade sentada, a cadeira de rodas tem por finalidade proporcionar às pessoas com algum tipo de limitação o ato de ir e vir, o acesso às oportunidades e o desenvolvimento de suas capacidades para alcançar a autonomia e a independência, bem como possibilitar que os indivíduos possam integrar-se à sociedade (AMORIM, 2009).

Atualmente, têm-se disponibilizado no mercado diversos modelos de cadeira de rodas para sanar os mais variados graus de necessidade do usuário. Mello (1999, p. 416) refere que,

[...] somente uma análise criteriosa das necessidades do cliente permitirá a indicação de um produto adequado. Existe um grande número de produtos que permitem montar sistemas individualizados. São usados materiais diversos como espumas de densidades diferentes e viscoelásticas, gel, silicones, ar, isoladamente ou combinados entre si em busca do sistema ideal para cada usuário. Esta prática tem se desenvolvido bastante na última década no Brasil. Já é possível encontrar no mercado brasileiro todas as grandes marcas de sistemas de assento (leia-se almofadas e encostos e sistemas especiais) disponíveis no mercado internacional. Entretanto, há uma carência de profissionais que dominem a técnica para prescrição individualizada desses produtos.

Mattos (2017) aborda em seu estudo sobre os componentes fundamentais de uma cadeira de rodas: apoio de braços e pés, encosto, freio de roda traseira e rodas dianteiras e traseiras. Também estabelece algumas considerações, tais como: o material mais utilizado para a fabricação da cadeira de rodas é o alumínio; titânio e fibra de carbono têm sido utilizados na confeç̧ão do produto, porém, devido ao preço elevado e ao processo de fabricação complexo, esses materiais são pouco viáveis; em relação aos pneus, os infláveis (pneumáticos) propiciam bom impacto e absorção de vibrações, entretanto os pneus sólidos requerem pouca manutenção e não apresentam qualquer risco de esvaziamento por perfurações.

A partir do que foi exposto, entende-se que a cadeira de rodas é um produto essencial para a vida diária da pessoa com deficiência motora, posto que, por passarem muito tempo em contato com o produto, o mesmo acaba tornando-se uma extensão do seu corpo. As características que a cadeira de 
rodas apresenta passam a ter suma importância na dinâmica do cotidiano, permitindo à criança o desenvolvimento de habilidades. Para tanto, é necessário que essa tecnologia assistiva apresente adequações ergonômicas e de conforto para obter-se uma postura apropriada. Somente assim, haverá a distribuição equilibrada da pressão na superfície da pele.

\subsection{Aspectos ergonômicos e de conforto da cadeira de rodas}

Para introduzir a temática, uma definição concisa sobre a ergonomia é apresentada pela International Ergonomics Association (IEA, s.d., s.p.):

A ergonomia (ou fatores humanos) é a disciplina científica que se ocupa em compreender a interação entre os seres humanos e outros elementos de um sistema, bem como a profissão que aplica teoria, princípios, dados e métodos a projetos a fim de otimizar o bem-estar humano e o desempenho global.

Os principais objetivos da ergonomia são a satisfação e o conforto dos indivíduos, garantindo que o produto e/ou serviço não causem problemas à saúde (CORRÊA; BOLETTI, 2015). Ainda, de acordo com os autores, a ergonomia engloba um contexto organizacional, psicossocial e político de um sistema.

O Design Universal e a ergonomia se complementam, pois a segunda visa adaptar os produtos e as atividades às pessoas, promovendo segurança, conforto e eficácia no uso, enquanto o design possibilita a criação desses produtos, inovando e planejando as características desejadas para o projeto (GOMES FILHO, 2003). Segundo Amorim (2009), é somente com a interação efetiva entre essas duas áreas que se torna possível acessibilidade, autonomia e independência.

Nos projetos de design, é necessário observar alguns requisitos ergonômicos, tais como:

[...] conforto postural; adequação dimensional; segurança no uso; facilidade de manipulação; compatibilidade de movimentação; minimização de esforços adicionais, racionalização e funcionalidade do arranjo físico dos componentes; facilitação da manutenção; apropriação do campo visual; legibilidade, visibilidade e compreensibilidade dos caracteres alfanuméricos e dos símbolos iconográficos; lógica 
do processamento cognitivo; objetivação da tarefa e qualidade do ambiente físico, químico e arquitetural. (MONT'ALVÃO; DAMAZIO, 2012, p. 20-1).

Pelo ponto de vista da ergonomia, conforme comentam Mont'Alvão e Damazio (2012, p. 17), a satisfação do usuário na interação com os produtos está relacionada com a usabilidade e o conforto físico. Ilda e Guimarães (2016, p. 241) definem o conforto como uma "sensação subjetiva de bem-estar, produzida quando não há nenhuma tensão localizada sobre o corpo". Para Côrrea e Boletti (2015, p. 16), o termo conforto "é abrangente e pode ser usado para designar várias situações, [...] se refere à sensação de bem-estar físico, alívio e comodidade. Já o termo desconforto se refere a tudo o que incomoda, distrai e atrapalha o bem-estar".

Em se tratando do conforto do assento, ele dependerá de diversos fatores, dentre os quais, cita-se a preferência individual. Portanto torna-se difícil pontuar as características determinantes, sendo essencial que haja disponível no mercado uma gama variada de assentos adequados para cada finalidade de uso, com o propósito de oportunizar melhor adaptação do usuário a um (IIDA; GUIMARÃES, 2016).

\subsection{Estigma, bullying e exclusão social}

Historicamente, foram os gregos que criaram o termo estigma para caracterizar sinais corporais que evidenciavam algo de extraordinário ou mau sobre o status moral de quem os possuía (GOFFMAN, 1988). De acordo com Ferreira (2008, p. 231), o conceito de estigma é uma "cicatriz" e/ ou "sinal" e o ato de estigmatizar, refere-se a "censurar" e/ou "condenar" algo ou alguém.

Segundo Mattos (2017), o design da cadeira de rodas interfere na avaliação do usuário pelo corpo social. Conforme o autor, esse julgamento pode ser positivo ou negativo, contribuindo para a minimização ou maximização do estigma sofrido por esse indivíduo. Tais rótulos implicam violência que se manifesta através da prática do bullying. De origem inglesa e ainda sem tradução específica para o português, o termo é utilizado para qualificar 
comportamentos violentos no âmbito social e familiar, seja em forma de agressão, assédio e/ou ação desrespeitosa, praticada de forma recorrente e intencional por parte do agressor (SILVA, 2010).

Em um estudo feito por Silva, Caramaschi e Valle (2014), ser usuário de cadeira de rodas foi mencionado como uma das características físicas mais propensas para tornar a criança alvo de discriminação. A prática do bullying tende a intensificar problemas psicológicos no público infantil usuário dessa tecnologia assistiva, podendo levá-lo a quadros graves de transtornos psíquicos e/ou comportamentais (SILVA, 2010), fazendo com que ele tenha múltiplas experiências de exclusão social.

A escassez de conhecimento e informação do corpo social sobre a deficiência colabora para constituir o pensamento de que esta deve ser vista e tratada como um problema, fato esse que necessita de muito esforço para que a população venha a superar o estigma imposto. Dentro de um cenário de exclusão, a pessoa com deficiência acaba impossibilitada de fazer interferências na dinâmica social (MARTINS, 2008), negando-Ihe o direito de vivenciar interações, o que causa confusão, desconfiança, depressão e hostilidade (GOFFMAN, 1988). Nesse sentido, a exclusão acaba sendo um "sintoma grave de uma transformação social que vem rapidamente fazendo de todos os seres humanos seres descartáveis, reduzidos à condição de coisa, forma extrema de vivência da alienação e da coisificação da pessoa" (MARTINS, 2008, p. 20). Sendo assim, é imprescindível que se discutam os processos de exclusão/ inclusão social sob as diversas perspectivas, incluindo o design ergonômico.

\subsection{Design emocional, ludicidade e inclusão social}

As interações humanas são envolvidas por emoções, o que faz com que elas ganhem papel essencial no cotidiano, auxiliando no julgamento de um contexto positivo ou negativo. Conforme Norman (2008, p. 38-9), as emoções amparam a tomada de decisões, posto que "emoções positivas são tão importantes quanto as negativas". Os produtos não são neutros, sendo impossível separá-los das nossas emoções, afinal eles interferem em nossos sentimentos, seja positivamente ou negativamente (DAMÁSIO, 2000).

O ser humano tende a associar emoção com beleza através da constru- 
O design da cadeira de rodas infantil e o processo de exclusão/inclusão social: uma revisão integrativa da literatura

ção de objetos atrativos visualmente. Porém, de acordo com Norman (2008), por mais que essas qualidades sejam notáveis, não são elas que impulsionam os indivíduos no cotidiano. As pessoas desejam os produtos em razão do sentimento que eles proporcionam, afinal, "as emoções refletem nossas experiências pessoais, associações e lembranças" (NORMAN, 2008, p. 68). Logo, evidencia-se que, além de esteticamente atrativo, o produto deve apresentar funcionalidade e aplicação de conceitos de ergonomia, além de um preço apropriado e acessível.

Mattos (2017) relata em seu estudo que foi possível perceber a conexão entre as funções estética e simbólica, sendo essa segunda determinada pelas funções psíquicas, sociais e de valores espirituais. Ainda, conforme o mesmo autor, a percepção estética da cadeira de rodas guia o usuário a determinado julgamento simbólico pelo corpo social, evocando impressões errôneas de enfermidade e dependência. Logo, a aparência desse objeto pode interferir nas suas interações sociais cotidianas, pois, segundo a sua pesquisa, alguns modelos tendem a ser associados a hospitais e clínicas; outros, por sua vez, possuem maior aceitação. Portanto a aparência afere que os aspectos de design da cadeira de rodas, que influenciam positivamente o seu usuário, referem à ampliação da tabela de cores (não se restringindo apenas ao branco e preto), apresentem formas orgânicas ou esportivas, assentos mais espessos que transmitam conforto e uma aparência resistente que transpareça solidez e segurança.

Norman (2008) comenta que a beleza, a diversão e o prazer produzem o sentimento de alegria, essencial para a curiosidade das pessoas e para o aprendizado, beneficiando na lida com o estresse. O lúdico está muito presente nos produtos direcionados ao público infantil. Ferreira (2008, p. 318) define que o termo lúdico se refere a "jogos, brinquedos e divertimentos". Já o Dicionário Informal (2012, s.p.) entende que ludicidade é uma "forma de desenvolver a criatividade, os conhecimentos, [...]. O intuito é educar, ensinar, se divertindo e interagindo com os outros".

O design de produtos destinado às pessoas com deficiência evoluiu, porém, conforme Senna (2012), ainda de forma não satisfatória, limitando-se apenas aos parâmetros funcionais (demandas relacionadas à ergonomia, usabilidade e manufatura), sem considerar a opinião dos usuários durante o 
processo de concepção. Também, o autor afirma que as crianças apresentam necessidades diferentes das dos adultos. Assim, supõe-se que a cadeira de rodas deve proporcionar diversão, independência na locomoção e apresentar aspectos que facilitem a inclusão, para que o público infantil possa criar contato físico com outras crianças, consciência espacial, coordenação motora e percepção visual.

Essa interação entre a criança, a cadeira de rodas e a ludicidade pode vir a ser um movimento para a construção da inclusão ao corpo social nos múltiplos espaços, posto que o ato de incluir colabora na concepção de uma nova sociedade que preza por transformações, sejam elas de níveis micro ou macro, abrangendo desde os ambientes físicos (espaços internos e externos, equipamentos, aparelhos e utensílios, mobiliário e meios de transporte) até a mentalidade das pessoas, incluindo a própria pessoa com deficiência (SASSAKI, 2010).

Para Amorim (2009), a integração social de pessoas com deficiência vem gerando o interesse pela concepção de novos produtos e adequação dos espaços, resultando na melhoria da acessibilidade para elas. Conforme Schmitt (2010), o ambiente escolar é o local da fusão da pluralidade de culturas e da complexidade das interações humanas. É onde o processo da exclusão/inclusão social da criança com deficiência emerge, pois é o primeiro lugar de convivência da qual ela participa depois do ambiente familiar. É nesse espaço que ela terá a oportunidade de se relacionar com outros indivíduos e de aprender/desenvolver a sociabilidade. Além disso, de acordo com a autora, um fato positivo para a inclusão escolar é de que o corpo social tenha a consciência do direito de o aluno com deficiência acessar a mesma escola e sala de aula que outras crianças frequentam. Porém deve-se assegurar que esse corpo social tenha auxílio para suprir as suas dificuldades para que não haja prejuízo ao desenvolvimento da criança, em relação ao seu direito à igualdade, cidadania e dignidade, visto que as escolas de qualidade são espaços educativos que constroem personalidades autônomas e críticas, lugar onde as crianças se desenvolvem para se tornarem adultos.

\subsection{Redesenho da cadeira de rodas}


Dos quatro estudos selecionados, apenas Amorim (2009) e Senna (2012) projetaram uma cadeira de rodas destinada ao público infantil. Buscando promover a possibilidade da união entre as três esferas multidisciplinares distintas, a pesquisa de Amorim (2009) reuniu as áreas da saúde, engenharia e desenho industrial para pesquisar e projetar o seu produto de mobilidade sentada. Inicialmente, a autora buscou elementos para compor a estruturação teórica. Após realizada a análise dos dados, a autora, na sequência, realizou a prototipação em 3D do redesenho da cadeira de rodas infantil que viesse a ser adaptada para o maior número de especificidades dos usuários abrangidos no seu estudo.

Tendo como foco a concepção de um recurso de tecnologia assistiva para o ambiente escolar de uma criança com deficiência física, Senna (2012) mencionou que o modelo da maioria das cadeiras de rodas destinada ao público infantil disponíveis no mercado nacional é do tipo "comum", sendo que, elas são produzidas há mais de 40 anos. Por sofrer somente alterações superficiais, a estrutura básica manteve-se inalterada durante todo esse período (40 anos) com as seguintes características: são estruturas tubulares que apresentam apoio tradicional existente entre rodas ou com o chassi cruzado, visando auxiliar na compactação e no transporte. Em contraponto, o mercado internacional oferta produtos mais atrativos e individualizados, em que se busca atender as necessidades específicas de cada usuário. Todavia a viabilização da importação desses equipamentos para o Brasil não é uma alternativa acessível devido ao alto valor, além de que, eles foram projetados de acordo com as características ambientais, culturais, econômicas e sociais de seu país de origem.

A cadeira de rodas proposta por Amorim (2009) possui alguns sistemas, tais como: frestas para engate de cinto de segurança em veículos automotores; borracha de vedação do cano; pegas de deslocamento da estrutura; engate e regulador de posição e ângulo do assento em relação à estrutura; engates para correias auxiliares para prender os pés; barra de reforço que auxilia na integridade da estrutura da cadeira e aumenta a segurança do encosto; regulagem do ângulo do assento; regulador de distância da base dos pés; regulador do ângulo e posição da base dos pés; corrediça de regulagem de distância do 
assento; barra de reforço removível para manter a estrutura da base; regulador de ângulo da estrutura da cadeira e bandeja metálica para portar itens e pertences da criança e do responsável. Ainda, o conceito final apresentando abrangeu uma mesinha de apoio, tanto para refeições como para atividades cotidianas, além de cinto peitoral, pélvico e para os pés. Também, o produto pode apresentar a aplicação de um tema infantil no seu estofado ou a cor desejada. Essa cadeira de rodas permite a utilização e a troca de capas acolchoadas no assento e no encontro, facilitando a manutenção da limpeza.

Em relação aos quesitos ergonômicos do produto resultante da pesquisa de Senna (2012), algumas medidas foram necessárias para auxiliar na sua configuração: largura do quadril, profundidade do assento, medida de perna e altura dos ombros e medida com base na escápula. Vale ainda ressaltar que esse projeto foi destinado para uma criança específica, sendo utilizadas medidas pertinentes ao caso em questão. As principais considerações positivas referentes a esse projeto são o baixo peso estrutural, posicionamento adequado do usuário, regulagem da altura e redução no esforço físico. Esse protótipo, portanto, obteve resultados satisfatórios, tendo dados que poderão contribuir para futuros estudos.

Apesar de ambos os autores fazerem apontamentos positivos para contribuir no redesenho da cadeira de rodas infantil tendo como premissa a melhoria da qualidade de vida através dessa TA, como forma de auxiliar no processo de inclusão das crianças com deficiência física ao corpo social, é salientado que não houve contemplação significativa da aplicabilidade de características lúdicas. Isso indica que ainda há muito a ser problematizado em torno dessa abordagem.

\section{CONSIDERAÇÕES FINAIS}

A partir do cenário exposto, nota-se que a cadeira de rodas é um produto essencial na vida das pessoas com deficiência motora por fazer parte das suas atividades diárias. Essa TA permite o ir e vir possibilitando maior autonomia a quem a utiliza, além de oportunizar ao indivíduo que se inclua e se faça presente ao corpo social.

Por constituir um campo que está recebendo novos olhares, acredita- 
O design da cadeira de rodas infantil e o processo de exclusão/inclusão social: uma revisão integrativa da literatura

-se que, atualmente, diferentes padrões comportamentais culturais estão sendo inseridos no contexto brasileiro sobre a deficiência. Isso significa que há maior preocupação com o bem-estar, saúde e a inclusão da criança que utiliza a cadeira de rodas como parte de seu corpo para desbravar o mundo ao seu redor, seja através da inserção de novos códigos, ferramentas e/ou produtos.

Com relação à aplicação do aspecto lúdico na cadeira de rodas, já ocorrem algumas reflexões em nível teórico, porém ainda são carentes de bibliografias que abordem especificamente sobre esse assunto. Por sua vez, essa aplicação pode ser uma forma de revelar a identidade do indivíduo sem que para isso haja a linguagem verbal, vindo a tornar-se um elemento da sua personalidade.

O ludismo pode se apresentar de forma artística, divertida e prazerosa, contribuindo para a aprendizagem, o desenvolvimento e a memorização da criança. Além de despertar a curiosidade, pode vir a ser um facilitador na criação e manutenção de relações sociais. Também, permite aflorar a imaginação através do empoderamento de personagens, trazendo novas experiências e sensações, gerando novas significações para esse ser.

Entende-se que esses apontamentos possam vir a contribuir significativamente para a ampliação do debate de futuros estudos acerca da aplicabilidade dos aspectos lúdicos na cadeira de rodas destinada ao público infantil. Sendo assim, crê-se que seria pertinente avançar em novas pesquisas que contemplem o reprojeto da cadeira de rodas infantil levando em consideração os parâmetros ergonômicos, posto que o conforto é primordial para a promoção e manutenção da qualidade de vida, juntamente aos aspectos estéticos e lúdicos, favorecendo a interação com a sociedade e o sentimento de pertencimento nela.

\section{REFERÊNCIAS}

AMORIM, B. M. P. Uma contribuição crítica para o redesenho de cadeira de rodas adaptada para crianças e adolescentes com paralisia infantil. 2009. 180 p. Dissertação (Mestrado em Engenharia de Produção) - Centro de Tecnologia, Universidade Federal do Rio Grande do Norte (UFRN), Natal, 2009. 
ASSOCIAÇÃO BRASILEIRA DE NORMASTÉCNICAS (ABNT). NBR 9050:2004: Acessibilidade a edificações, mobiliário, espaços e equipamentos urbanos. Disponível em: https:// www.pessoacomdeficiencia.gov.br/app/sites/default/files/arquivos/\%5Bfield_ generico_imagens-filefield-description\%5D_24.pdf. Acesso em: 20 fev. 2018.

BENTO, A. Como fazer uma revisão da literatura: considerações teóricas e práticas. Revista JA, ano VII, n. 65, p. 42-4, 2012. Disponível em: http://www3.uma.pt/bento/ Repositorio/Revisaodaliteratura.pdf. Acesso em: 5 dez. 2017.

BERLESE, D. B.; BERLESE, D. B.; RENNER, J. S.; SANTOS, G. A.; SANFELICE, G. R. Aspectos sociais do corpo obeso. In: SANFELICE, G. R. (Org.). Qualidade de vida e inclusão social: aspectos relacionados à saúde. Saarbrücken, Germany: Novas Edições Acadêmicas, 2015.

BERSCH, R. Introdução à tecnologia assistiva. Porto Alegre, RS: CEDI - Centro Especializado em Desenvolvimento Infantil, 2009.

CAPES. Catálogo de teses e dissertações. 2016. Disponível em: http:// catalogodeteses.capes.gov.br/catalogo-teses/\#!/. Acesso em: 8 jan. 2018.

CÔRREA, V. M.; BOLETTI, R. R. Ergonomia: fundamentos e aplicações. Porto Alegre, RS: Bookman, 2015.

DAMÁSIO, A. O mistério da consciência: do corpo e das emoções do conhecimento de si. São Paulo: Companhia das Letras, 2000.

DICIONÁRIO INFORMAL. Ludicidade. 2012. Disponível em: http://www. dicionarioinformal.com.br/ludicidade/. Acesso em: 13 mar. 2018.

FERREIRA, A. B. H. Aurélio: o dicionário de língua portuguesa. 2. ed. Curitiba, PR: Positivo, 2008.

GOFFMAN, E. Estigma: notas sobre a manipulação da identidade deteriorada. 4. ed. Rio de Janeiro: Guanabara Koogan, 1988.

GOMES FILHO, J. Ergonomia do objeto: sistema técnico de leitura ergonômica. São Paulo: Escrituras, 2003.

HIRIGOYEN, M. F. Mal-estar no trabalho: redefinindo o assédio moral. Rio de Janeiro: Bertrand Brasil, 2002.

IIDA, I.; GUIMARÃES, L. B. M. Ergonomia: projeto e produção. 3. ed. São Paulo: Edgard Blücher, 2016. 
O design da cadeira de rodas infantil e o processo de exclusão/inclusão social: uma revisão integrativa da literatura

INSTITUTO BRASILEIRO DE GEOGRAFIA E ESTATÍSTICA (IBGE). Censo demográfico 2010: características gerais da população, religião e pessoas com deficiência. Rio de Janeiro: IBGE, 2010.

INTERNATIONAL ERGONOMICS ASSOCIATION (IEA). Definition and domains of ergonomics. [s.d.]. Disponível em: http://www.iea.cc/whats/. Acesso em: 8 mar. 2018.

KROEMER, K. H. E.; GRANDJEAN, E. Manual de ergonomia: adaptando o trabalho ao homem. 5. ed. Porto Alegre, RS: Bookman, 2005.

LARANJEIRA, F. O.; ALMEIDA, R. T. Utilização de órteses e meios auxiliares de locomoção no sistema único de saúde. In: OLIVEIRA, A. I. A.; LOURENÇO, M. Q.; LOURENÇO, M. G. F. (Org.). Perspectiva da Tecnologia Assistiva no Brasil: pesquisa e prática. Belém, PA: EDUEPA, 2008.

MARTINS, J. S. A sociedade vista do abismo: novos estudos sobre exclusão, pobreza e classes sociais. 3. ed. Petrópolis, RJ: Vozes, 2008.

MASINI, E. F. S.; BECKER, E.; PINTO, E. B.; AMARAL, L. A. Deficiência: alternativas de intervenção. São Paulo: Casa do Psicólogo, 1997.

MATTOS, L. M. Julgamento visual de cadeiras de rodas: contribuições para o design de produtos assistivos. 2017. 81 p. Dissertação (Mestrado em Design)- Faculdade Arquitetura, Artes e Comunicação, Universidade Estadual Paulista (UNESP), Bauru, SP, 2017.

MELLO, M. A. F. Tecnologia assistiva. In: GREVE, J. M. D.; AMATUZZI, M. M. Medicina de reabilitação aplicada à ortopedia e traumatologia. 1. ed. São Paulo: Roca, 1999.

MENDES, K. D. S.; SILVEIRA, R. C. C. P.; GALVÃO, C. M. Revisão integrativa: método de pesquisa para a incorporação de evidências na saúde e na enfermagem. Texto \& Contexto - Enfermagem, Florianópolis, SC, v. 17, n. 4, p. 758-64, out./dez. 2008. Disponível em: http://www.scielo.br/scielo.php?script=sci_arttext\&pid =S0104-07072008000400018. Acesso em: 5 dez. 2017.

MINAYO, M. C.; HARTZ, Z. M. A.; BUSS, P. M. Qualidade de vida e saúde: um debate necessário. Ciência \& Saúde Coletiva, Rio de Janeiro, v. 5, n. 1, p. 7-18, 2000. Disponível em: http://www.scielo.br/scielo.php?script=sci_arttext\&pid=S141381232000000100002\&lng=en\&nrm=iso\&tlng=pt. Acesso em: 7 dez. 2017.

MONT'ALVÃO, C.; DAMAZIO, V. Design, ergonomia, emoção. 3. ed. Rio de Janeiro: Mauad, 2012. 
NORMAN, D. A. Design emocional: por que adoramos (ou detestamos) os objetos do dia-a-dia. Rio de Janeiro: Rocco, 2008.

OLIVEIRA, L. M. B. Cartilha do Censo 2010: pessoas com deficiência. Brasília: Secretaria de Direitos Humanos da Presidência da República (SDH/PR), Secretaria Nacional de Promoção dos Direitos da Pessoa com Deficiência (SNPD), CoordenaçãoGeral do Sistema de Informações sobre a Pessoa com Deficiência, 2012.

RUSSO, B.; HEKKERT, P. Sobre amar um produto: os princípios fundamentais. In: MONT'ALVAO, C.; DAMAZIO, V. (Org.). Design, ergonomia e emoção. Rio de Janeiro: FAPERJ/Mauad X, 2008.

SASSAKI, R. K. Inclusão: construindo uma sociedade para todos. 8. ed. Rio de Janeiro: WVA, 2010.

SCHMITT, N. L. Tecnologias assistivas no cotidiano da criança com deficiência física: potencialidades e inclusão social. 2010. 106 f. Dissertação (Mestrado em Inclusão Social e Acessibilidade) - Universidade Feevale, Novo Hamburgo, RS, 2010.

SENNA, C. E. Tecnologia assistiva nas classes comuns do ensino regular: contribuições no design de sistemas de mobilidade infantil para auxílio nas interações sociais. 2012. 127 f. Dissertação (Mestrado em Design) - Escola de Engenharia, Universidade Federal do Rio Grande do Sul (UFRGS), Porto Alegre, 2012.

SILVA, A. B. B. Bullying: mentes perigosas nas escolas. Rio de Janeiro: Fontanar, 2010.

SILVA, G. F.; CARAMASCHI, S.; VALLE, T. G. M. Características físicas das vítimas de bullying. In: SEMANA DE PSICOLOGIA UNESP/BAURU-SP, 21., e CONGRESSO DE PSICOLOGIA UNESP/BAURU-SP, 8.: RELAÇÕES DE PODER E A PSICOLOGIA COMO INSTRUMENTO DE TRANSFORMAÇÃO SOCIAL. Anais [...]. Bauru, SP: Universidade Estadual Paulista (UNESP), 2014. 